\title{
Clinical Outcomes of Resectable Esophageal Cancer with Supraclavicular Lymph Node Metastases Treated with Curative Intent
}

\author{
YOSHITAKA HONMA ${ }^{1}$, NOBUKAZU HOKAMURA ${ }^{2}$, KENGO NAGASHIMA $^{3}$, KAZUKI SUDO $^{1}$, \\ HIROKAZU SHOJI ${ }^{1}$, SATORU IWASA ${ }^{1}$, ATSUO TAKASHIMA ${ }^{1}$, KEN KATO $^{1}$, \\ TETSUYA HAMAGUCHI ${ }^{1}$, NARIKAZU BOKU ${ }^{1}$, REI UMEZAWA ${ }^{4}$, YOSHINORI ITO ${ }^{4}$, \\ JUN ITAMI $^{4}$, KAZUO KOYANAGI ${ }^{2}$, HIROYASU IGAKI ${ }^{2}$ and YUJI TACHIMORI ${ }^{2}$ \\ ${ }^{1}$ Gastrointestinal Medical Oncology Division, ${ }^{2}$ Esophageal Surgery Division, \\ ${ }^{4}$ Department of Radiation Oncology, National Cancer Center Hospital, Tokyo, Japan; \\ ${ }^{3}$ Department of Global Clinical Research, Graduate School of Medicine, Chiba University, Chiba, Japan
}

\begin{abstract}
Background: In the seventh edition of the Union for International Cancer Control (UICC) TNM classification, supraclavicular lymph node (SCLN) in regard to thoracic esophageal cancer $(E C)$ is regarded as a distant organ, therefore, if resectable, SCLN metastasis is considered a candidate for systemic chemotherapy. The purpose of this study was to clarify the survival outcome in patients with resectable thoracic EC with SCLN metastases (MILYM) treated with curative intent. Patients and Methods: Clinical outcomes in patients with resectable thoracic EC with SCLN metastases (MILYM) treated by esophagectomy or definitive chemoradiotherapy (dCRT) were retrospectively analyzed. Results: A total of 102 patients were divided in three groups: Surgery with perioperative therapy, $n=45$; surgery alone, $n=19$; and $d C R T, n=38$. Overall, median progression-free survival and median survival time were 9.3 and 26.7 months, respectively. The median survival time was 27.5 months in the group treated with surgery with perioperative treatment, 50.6 months in those treated with surgery alone, and 22 months in the dCRT group. No significant survival difference was seen among the three groups. Conclusion: Over $30 \%$ of patients with resectable MILYM treated with curative intent achieved long-term survival.
\end{abstract}

Although perioperative chemotherapy or chemoradiotherapy before or after surgery is a standard treatment for advanced

Correspondence to: Yoshitaka Honma, MD, Gastrointestinal Medical Oncology Division, National Cancer Center Hospital, 5-11 Tsukiji, Chuo-ku, Tokyo 104-0045, Japan. Tel: +81 335422511, Fax: +81 335423815, e-mail: yohonma@ncc.go.jp

Key Words: Esophageal cancer, supraclavicular lymph node metastases, surgery, chemoradiotherapy. resectable esophageal cancer (EC), definitive chemoradiotherapy (dCRT) is performed alternatively as an optional treatment (1). Clinical outcomes of local treatment such as surgery for EC generally depend on the clinical stage. Surgical outcomes with or without perioperative chemotherapy or chemoradiotherapy for patients with supraclavicular lymph node (SCLN) metastases were thought to be dismal in Western countries (2). Thus, in the seventh edition of the UICC TNM classification, SCLN metastases of thoracic EC are regarded as distant metastases (3). Therefore, according to the National Comprehensive Cancer Network guidelines (4), thoracic EC with SCLN metastases (M1LYM) is considered a candidate for systemic chemotherapy in Western countries.

In contrast, the Japanese multi-institutional nationwide registry of EC showed that $14.5 \%$ of patients who underwent esophagectomy had SCLN metastases histologically, which means some SCLN metastases can be recognized as being resectable, similarly to other regional nodes (5). Moreover, previous reports indicated that some patients with SCLN metastases who underwent esophagectomy achieved longterm survival, and SCLN metastases had little prognostic impact for EC $(5,6)$. Thus, in the 10th edition of the Japanese classification of EC (7), as SCLNs are regarded as regional lymph nodes in thoracic EC, M1LYM is usually treated with curative intent in Japan.

While the therapeutic value of adding local treatment (surgery or radiotherapy) in M1LYM judged by pretreatment imaging to be resectable remains controversial, prognosis should be anticipated for determining the treatment strategy, whether local or systemic therapy. The purpose of this study was to clarify the survival outcome of patients with clinically judged resectable M1LYM treated with curative intent (esophagectomy with/without perioperative treatment, or dCRT). 
Table I. Patient characteristics.

\begin{tabular}{|c|c|c|c|c|c|}
\hline Characteristic & All $(\mathrm{N}=102)$ & $\mathrm{S} / \mathrm{Tx}(\mathrm{N}=45)$ & Surgery alone $(\mathrm{N}=19)$ & $\mathrm{dCRT}(\mathrm{N}=38)$ & $p$-Value \\
\hline Median age (range), years & $64(34-81)$ & $63(37-80)$ & $65(46-81)$ & $64(49-77)$ & 0.461 \\
\hline$<65$ Years, $\mathrm{n}(\%)$ & $56(54.9 \%)$ & $27(60 \%)$ & $8(42.1 \%)$ & $21(55.3 \%)$ & \\
\hline$\geq 65$ Years, $\mathrm{n}(\%)$ & $46(45.1 \%)$ & $18(40 \%)$ & $11(57.9 \%)$ & $17(44.7 \%)$ & \\
\hline Gender, n $(\%)$ & & & & & 0.444 \\
\hline Male & $94(92.2 \%)$ & $40(88.9 \%)$ & $19(100 \%)$ & $35(92.1 \%)$ & \\
\hline Female & $8(7.8 \%)$ & $5(11.1 \%)$ & $0(0 \%)$ & $3(7.9 \%)$ & \\
\hline Performance status, n (\%) & & & & & 0.225 \\
\hline 0 & $31(30.4 \%)$ & $14(31.1 \%)$ & $7(36.8 \%)$ & $10(26.3 \%)$ & \\
\hline 1 & $68(66.7 \%)$ & $30(66.7 \%)$ & $10(52.6 \%)$ & $28(73.7 \%)$ & \\
\hline 2 & $3(2.9 \%)$ & $1(2.2 \%)$ & $2(10.6 \%)$ & $0(0 \%)$ & \\
\hline Tumor location, n (\%) & & & & & 0.983 \\
\hline Upper & $20(19.7 \%)$ & $10(22.2 \%)$ & $3(15.8 \%)$ & $7(18.4 \%)$ & \\
\hline Middle & $63(61.7 \%)$ & $27(60 \%)$ & $12(63.1 \%)$ & $24(63.2 \%)$ & \\
\hline Lower & $19(19.6 \%)$ & $8(17.8 \%)$ & $4(21.1 \%)$ & $7(18.4 \%)$ & \\
\hline Clinical T-stage, $\mathrm{n}(\%)$ & & & & & 0.226 \\
\hline $\mathrm{T} 1$ & $16(15.7 \%)$ & $4(8.9 \%)$ & $6(31.6 \%)$ & $6(15.8 \%)$ & \\
\hline $\mathrm{T} 2$ & $5(4.9 \%)$ & $3(6.7 \%)$ & $0(0 \%)$ & $2(5.3 \%)$ & \\
\hline $\mathrm{T} 3$ & $81(79.4 \%)$ & $38(84.4 \%)$ & $13(68.4 \%)$ & $30(78.9 \%)$ & \\
\hline Clinical N-stage, n (\%) & & & & & 0.235 \\
\hline No & $10(9.8 \%)$ & $5(11.1 \%)$ & $2(10.5 \%)$ & $3(7.9 \%)$ & \\
\hline N1 & $47(46.1 \%)$ & $20(44.5 \%)$ & $11(57.9 \%)$ & $16(42.1 \%)$ & \\
\hline $\mathrm{N} 2$ & $40(39.2 \%)$ & $15(33.3 \%)$ & $6(31.6 \%)$ & $19(50 \%)$ & \\
\hline N3 & $5(4.9 \%)$ & $5(11.1 \%)$ & $0(0 \%)$ & $0(0 \%)$ & \\
\hline cIM, n $(\%)$ & & & & & 0.124 \\
\hline Negative & $88(86.3 \%)$ & $38(84.4 \%)$ & $19(100 \%)$ & $31(81.6 \%)$ & \\
\hline Positive & $14(13.7 \%)$ & $7(15.6 \%)$ & $0(0 \%)$ & $7(18.4 \%)$ & \\
\hline WBC, n (\%) & & & & & 0.602 \\
\hline$\leq 8000 / \mathrm{mm}^{3}$ & $75(73.5 \%)$ & $35(77.8 \%)$ & $14(73.7 \%)$ & $26(68.4 \%)$ & \\
\hline$>8000 / \mathrm{mm}^{3}$ & $26(25.5 \%)$ & $10(22.2 \%)$ & $4(21 \%)$ & $12(31.6 \%)$ & \\
\hline Unknown & $1(1 \%)$ & $0(0 \%)$ & $1(5.3 \%)$ & $0(0 \%)$ & \\
\hline Albumin, n (\%) & & & & & 0.747 \\
\hline$<4.0 \mathrm{~g} / \mathrm{dl}$ & $30(29.4 \%)$ & $14(31.1 \%)$ & $4(21.1 \%)$ & $12(31.6 \%)$ & \\
\hline$\geq 4.0 \mathrm{~g} / \mathrm{dl}$ & $72(70.6 \%)$ & $31(68.9 \%)$ & $15(78.9 \%)$ & $26(68.4 \%)$ & \\
\hline
\end{tabular}

S/Tx: Surgery plus perioperative therapy; dCRT: definitive chemoradiotherapy; cIM: clinical intramural metastases.

\section{Patients and Methods}

Patient selection. We retrospectively analyzed patients with resectable M1LYM, detectable by imaging before treatment, who were initially treated by esophagectomy with/without perioperative treatment, or with dCRT at the National Cancer Center Hospital $(\mathrm{NCCH})$. Clinical data for this study were extracted from our database of consecutive patients. Clinical staging was determined at a multidisciplinary team conference based on the findings of upper gastrointestinal endoscopy (UGI), endoscopic ultrasonography, and cervico-thoracic-abdominal thin-slice computed tomography. Neck ultrasonography and ${ }^{18} \mathrm{~F}$-fluorodeoxyglucose positron-emission tomography were performed if necessary. Patients with cervical or abdominal EC, histology other than squamous cell carcinoma (SCC), unresectable (T4) disease, simultaneous advanced malignancies, or without detailed follow-up data were excluded. Surgical resectability was reviewed by two EC surgeons. This retrospective study was approved by the Institutional Review Boards of NCCH (2012-268).
Data collection and statistical analyses. Performance status (PS) was evaluated according to the Eastern Cooperative Oncology Group criteria (24). Clinical staging was classified according to the seventh edition of the UICC-TNM classification (3). A clinical complete response (cCR) after dCRT was defined according to the Response Evaluation Criteria in Solid Tumours (RECIST) guideline version 1.1 (25), when (i) no residual tumor was detected by UGI and CT, and (ii) no malignant cells were detected in biopsy specimens taken by UGI.

Overall survival (OS) was defined as the time from the date of initiating the first treatment to death (all causes) or was censored at the last date of confirmed survival. Progression-free survival (PFS) was defined as the time from the date of initiating the first treatment to the date of the first progression or death (all causes), whichever came first, or was censored at the last date of confirmed no progression. For patients who underwent salvage esophagectomy for non-progressive remnant disease after dCRT, incomplete (R1/2) surgery or disease recurrence after curative (R0) surgery were defined as PFS events. Locoregional relapse was defined as 


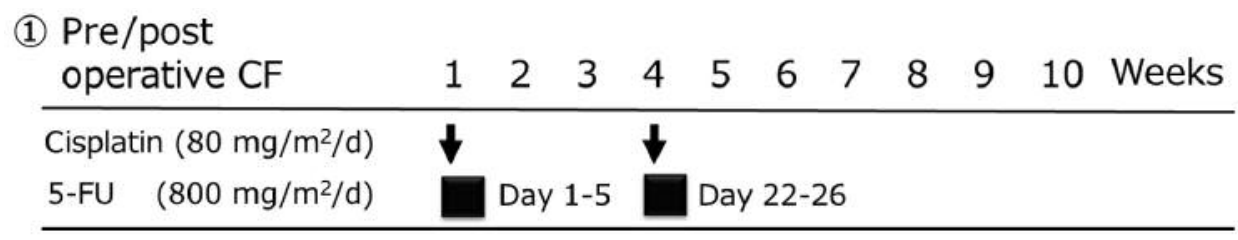

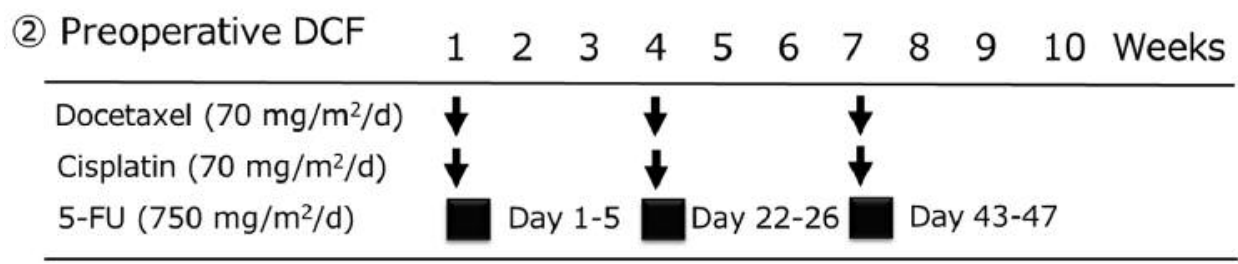

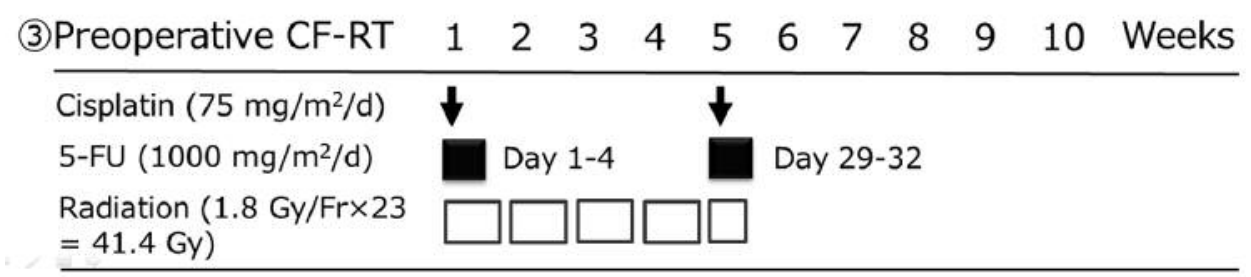

Figure 1. Regimens for perioperative treatment. 5-FU: 5-Fluorouracil.

recurrence inside of the surgical field for patients who underwent esophagectomy, and recurrence inside of the radiation field for patients who received dCRT.

Survival curves were drawn with the Kaplan-Meier method and compared by the log-rank test. Patient characteristics were compared with the Wilcoxon rank-sum test or Fisher's exact test, as appropriate. Univariate and multivariate analyses were performed with Cox regression models. From the clinical point-of-view, eight variables were included in the models: age, PS, tumor location, clinical T-stage, clinical $\mathrm{N}$-stage, clinical presence of intramural metastases (cIM), leukocyte (WBC) count $\left(>8,000 / \mathrm{mm}^{3}\right)$, and albumin $(\geq 4 \mathrm{~g} / \mathrm{dl})$. The proportional hazards assumption was confirmed by a score test (8). A two-sided $p$-value of less than 0.05 was deemed statistically significant. All statistical analyses were performed using SAS software (version 9.4; SAS Institute, Inc., Cary, NC, USA).

\section{Results}

Patient characteristics. Of 8467 patients with primary EC treated at NCCH from January 2001 to December 2012, data for 251 patients with SCLN metastases detectable by imaging without distant metastases were extracted. Of these patients, 149 were excluded because of cervical or abdominal EC in 48, histology other than SCC in 12, T4 disease in 79, simultaneous advanced malignancy in four, and due to lack of detailed follow-up data in six. Finally, a total of 102 patients were the subjects of our study. Patients were divided into three groups according to treatment modality: Surgery with perioperative therapy (S/Tx), surgery alone, and dCRT. There was no difference in the patient characteristics among the three groups (Table I).

Sixty-four $(62.7 \%)$ of the 102 patients underwent surgical treatment. Thirty-five $(54.7 \%)$ out of these 64 patients comprised the $\mathrm{S} / \mathrm{Tx}$ group (Figure 1): preoperative cisplatin plus 5-fluorouracil (CF) in 25 patients, preoperative docetaxel, cisplatin plus 5-fluorouracil (DCF) in six, preoperative CF-radiotherapy in two, and other regimens in two patients. Ten patients $(15.6 \%)$ received postoperative $\mathrm{CF}$. Nineteen patients $(29.7 \%)$ underwent surgery without perioperative treatment. In four out of the 45 patients in the $\mathrm{S} / \mathrm{Tx}$ group, and in one of 19 patients in the surgery-alone group, esophagectomy was performed with macroscopic residual tumor (R2). Another 59 patients who underwent curative esophagectomy underwent bilateral cervical neck lymphadenectomy. Hence, 38 out of the 102 patients received dCRT (Figure 2): standard CF-radiotherapy in 27 patients modified CF-radiotherapy in five, split CFradiotherapy in two, and other regimens in four patients. Twenty $(52.6 \%)$ of these patients achieved cCR.

Twenty-eight patients without preoperative treatment (10 in the S/Tx group and 18 in the group treated with surgery alone) underwent bilateral neck lymph node dissection. Pathological SCLN metastases were observed in 25 out of 28 patients, the positive predictive value of clinical diagnosis for SCLN metastases was $89.3 \%$. 


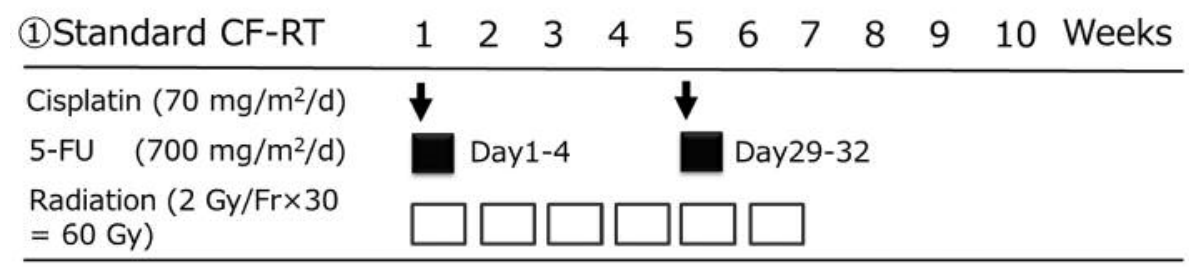

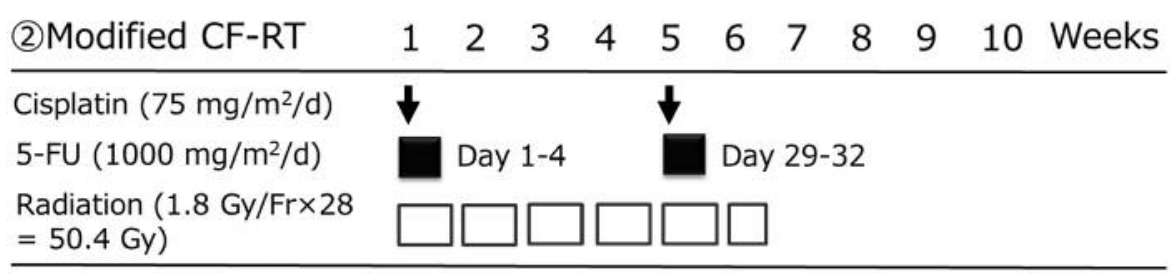

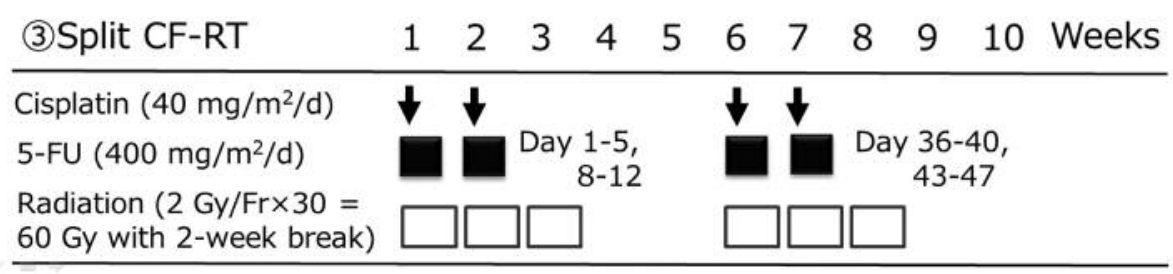

Figure 2. Regimens for definitive chemoradiotherapy. 5-FU: 5-Fluorouracil.

Analyses of survival data and prognostic factors. For the whole patient cohort, the median follow-up of survivors was 39.8 (range=9.4-136.7) months. The median PFS for the whole cohort was 9.3 months (1/3/5-year PFS: 43.6/33.6/25.6\%), for the S/Tx group 9.1 months (1/3/5-year PFS; $43.3 / 32.1 / 25.7 \%$ ), for the group treated with surgery alone 25.1 months (1/3/5-year PFS: 63.2/47.4/41.4\%), and for the dCRT group 8.5 months (1/3/5-year PFS: $34.2 / 28.4 / 17.8 \%$ ) (Figure 3). The median OS was 26.7 months (1/3/5-year OS: $81.1 / 44.8 / 34.8 \%)$ for the whole cohort, 27.5 months (1/3/5-year OS: $88.8 / 49.2 / 43 \%)$ in the $\mathrm{S} / \mathrm{Tx}$ group, 50.6 months (1/3/5-year OS: 78.9/52.6/46.8\%) in the surgery-alone group, and 22 months in the dCRT group (1/3/5-year OS: 73.2/35.1/20.5\%) (Figure 4). The surgery-alone group survived longer than the S/Tx and dCRT groups, although no significant survival difference was observed among the three groups by log-rank test (Figure 3: $p=0.2823$; Figure 4: $p=0.1383$ ). Moreover, in the subsets classified by tumor location, no significant survival difference was observed.

A multivariate analysis indicated that the depth of the primary lesion (clinical T3), advanced age ( $\geq 65$ years old), and high WBC count $\left(>8,000 / \mathrm{mm}^{3}\right)$ were independently associated with poor OS (Table II), whereas depth of primary lesion was independently associated with poor PFS (Table III) in patients with resectable M1LYM who were treated with curative intent.
Two patients who underwent esophagectomy $(3.1 \% ; 2 / 64)$ died within 30 days after surgery due to surgical complications (sepsis and suffocation by tracheal stenosis). On the other hand, no treatment-related death and severe late toxicities were observed in the dCRT groups.

Recurrence pattern and treatment after initial treatment relapse. In the S/Tx group, 24 out of 41 patients $(53.7 \%)$ experienced recurrence after curative surgery. Among these, locoregional relapse after R0 resection was observed in eight patients $(33.3 \%)$, distant relapse in six $(25 \%)$, and both local and distant relapse in nine $(37.5 \%$ ) (recurrence site of one patient was unknown). In the group treated with surgery alone, nine out of 18 patients $(50 \%)$ experienced recurrence: local in six $(67 \%)$ patients, distant in two $(22 \%)$, and both local and distant in one (11\%). In the dCRT group, 20 patients achieved cCR, and nine patients (45\%) experienced recurrence: local in four $(44 \%)$, distant in three $(33 \%)$, and both local and distant in one $(11 \%)$ (recurrence site of one patient was unknown).

Twenty-two out of 28 patients who experienced relapse after the initial treatment (recurrence: 24, non-curative resection: four) in the $\mathrm{S} / \mathrm{Tx}$ group and five out of 10 patients who experienced relapse after the initial treatment (recurrence: nine, non-curative resection: one) in the surgeryalone group received antitumor treatment. Eleven of them received CRT and one of them was alive without additional treatment. In the dCRT group, 12 out of 27 patients who 


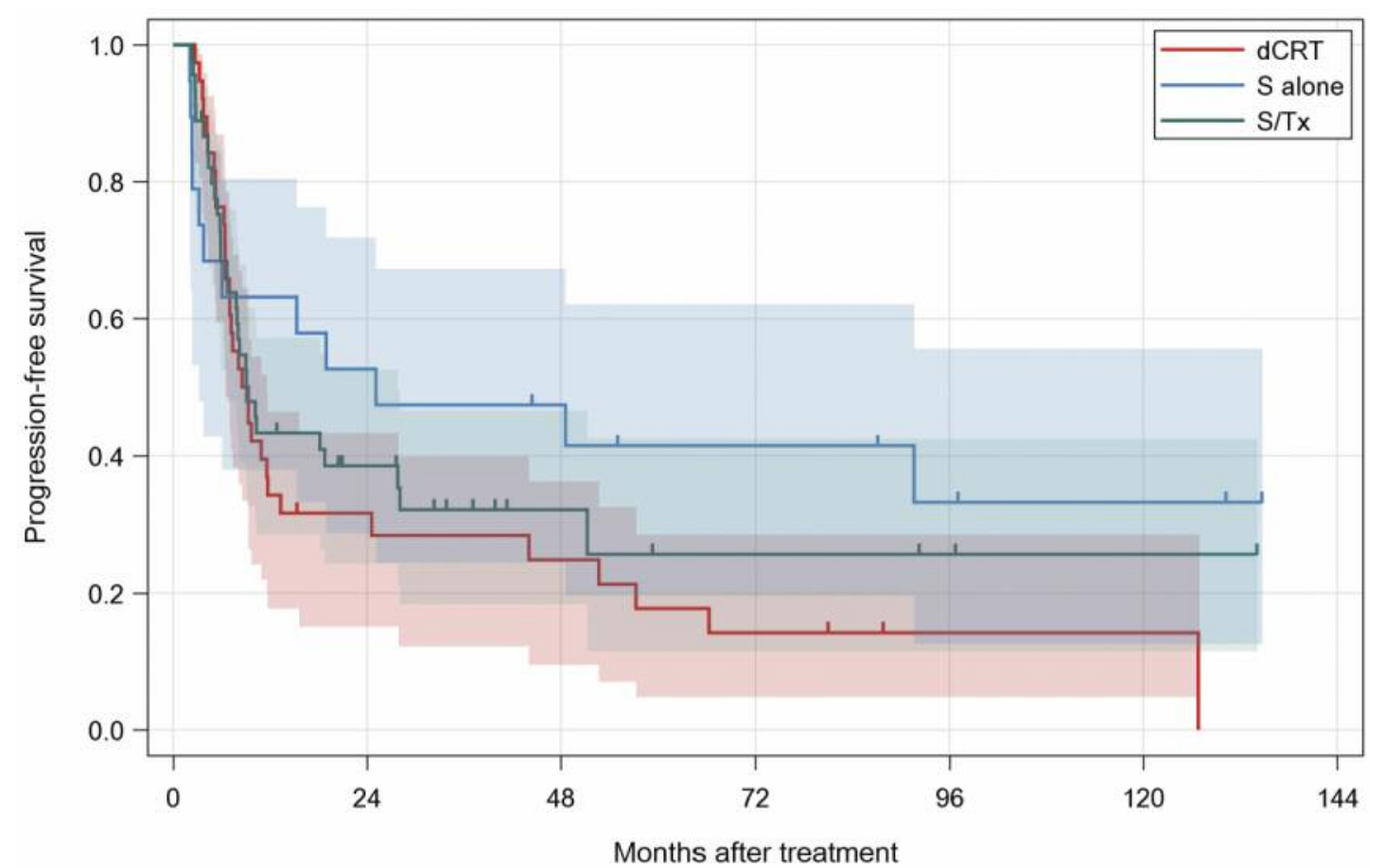

$\begin{array}{rcr} & \text { No. at risk } \\ \text { dCRT } & 38 & 10 \\ \text { S alone } & 19 & 10 \\ \text { S/Tx } & 45 & 13\end{array}$

$\begin{array}{ll}7 & 4 \\ 8 & 6 \\ 5 & 3\end{array}$

$\begin{array}{lll}1 & 1 & 0 \\ 4 & 3 & 0 \\ 2 & 1 & 0\end{array}$

Figure 3. Progression-free survival of patients according to therapy. dCRT: definitive chemoradiotherapy; S alone: surgery alone; S/Tx: surgery plus perioperative therapy.

experienced relapse after the initial treatment (recurrence after cCR: nine, non-CR: 18) received antitumor treatment. Four of them underwent salvage esophagectomy, two for locoregional relapse and two for remnant tumor, and one remained alive without a second relapse.

\section{Discussion}

In Japan, radical esophagectomy with extended lymphadenectomy has been performed for thoracic EC (9). From this precedent, detailed distribution of lymph node metastasis has been obtained, and $15-20 \%$ of surgical cases with thoracic EC with SCC histology have SCLN metastases $(5,6,10)$. One report showed patients with pathologically confirmed M1LYM did not have a worse prognosis than those with TNM-N3 who underwent esophagectomy with extended lymphadenectomy (5-year OS; M1LYM: 26.5 months, TNM-N3: 17.6 months) (6). Another study reported that the survival of patients with pathologically confirmed M1LYM who underwent esophagectomy was not too bleak (5-year OS: 24.1\%) and SCLN metastases was not a prognostic factor in multivariate analysis. Additionally, they noted SCLN had characteristics similar to other regional lymph nodes in terms of prognosis (5). In our study, over $30 \%$ of patients with resectable M1LYM treated with curative intent achieved long-term survival. Our 5-year survival rates seem to be better than those of the previous reports $(2,11)$. Locoregional treatment with curative intent was applied even for local failure after initial treatment. Previous reports showed that $10-20 \%$ of patients with local failure after initial surgery achieved cCR or long-term survival after dCRT $(12,13)$. It is speculated that the sequence of locoregional treatments for local failure, salvage esophagectomy or chemoradiotherapy, might contribute to favorable clinical outcomes. Compared with survival data of historical cohorts (14-17), our study shows that the clinical outcomes of patients with resectable M1LYM treated with curative intent are closer to those of localized disease rather than those of systemic disease (Table IV).

In our study, more cases achieving long-term survival were observed in the surgically-treated groups (5-year OS: $43 \%$ in the S/Tx group and $46.8 \%$ in the group treated 


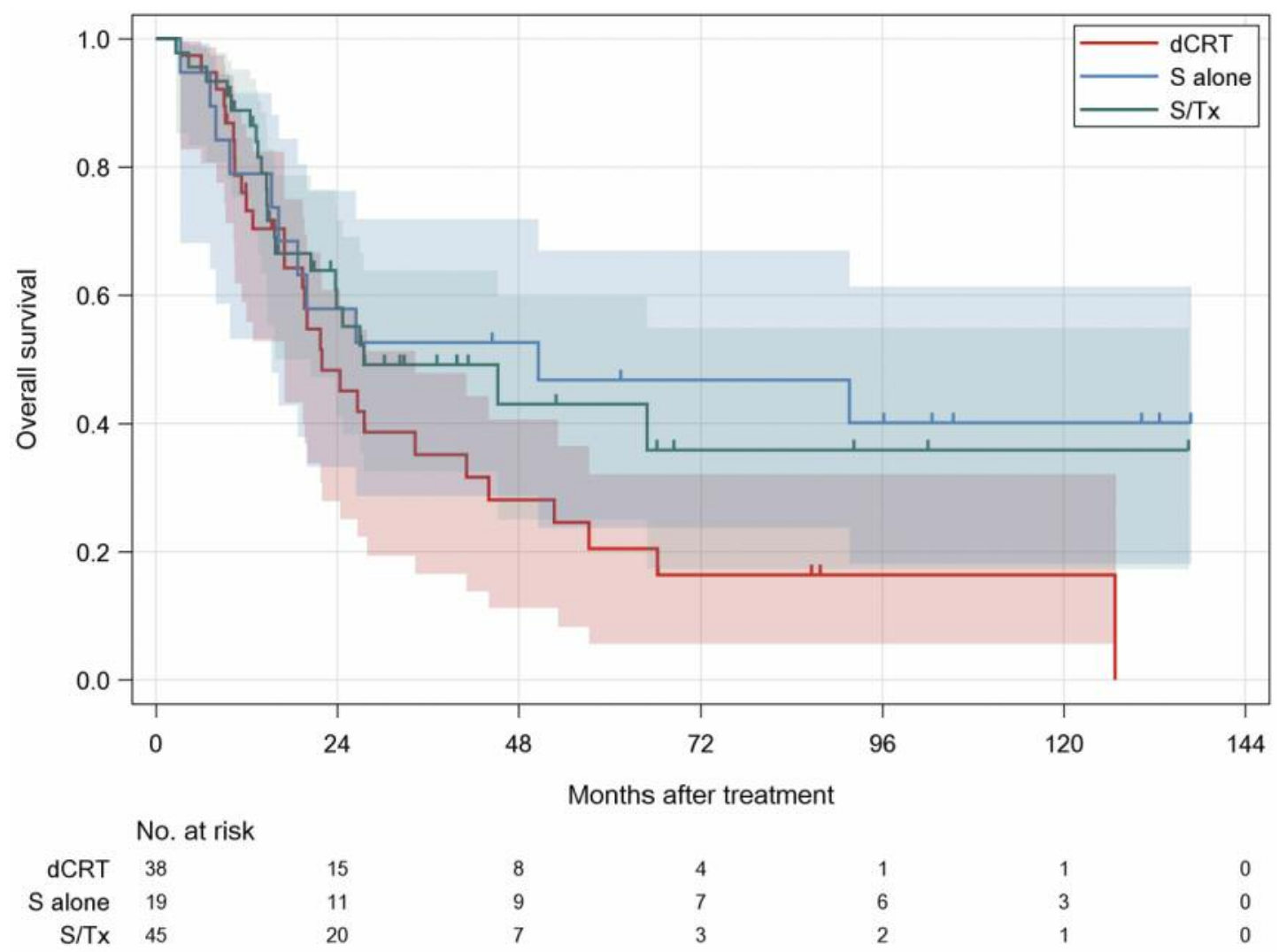

Figure 4. Overall survival of patients according to therapy. dCRT: definitive chemoradiotherapy; S alone: surgery alone; S/Tx: surgery plus perioperative therapy.

with surgery alone) than in the dCRT group (5-year OS: $20.5 \%$ ). There was no significant survival difference according to treatment by univariate analysis. It is inappropriate to compare survival by treatment modalities because selection bias might exist. Nineteen patients were treated with surgery alone, not a standard treatment for advanced thoracic EC. Seventeen of these patients underwent surgery before March 2008, confirming the result of a randomized controlled trial for the efficacy of neoadjuvant strategy (JCOG9907) in Japan (15). These 17 patients did not receive adjuvant $\mathrm{CT}$ x for the following reasons: poor PS after surgery in six, two or less pathologically positive lymph nodes in 10 , and patient refusal in one case. Another two patients did not receive neoadjuvant CTx because of renal impairment and patient refusal.

In our study, multivariate analysis demonstrated that a clinical depth of T3 was an independent negative prognostic factor, consistent with reports from both Japan and Western countries $(18,19)$. Recently, Yokota et al. showed that a preoperative clinical depth of T3 and low serum albumin
$(<4.0 \mathrm{~g} / \mathrm{dl})$ are independent prognostic factors for patients undergoing preoperative chemotherapy for advanced thoracic esophageal SCC, based on data from JCOG9907 (20). Our study also revealed that a clinical depth of T3 was one of the most powerful prognostic factors in patients with resectable M1LYM, but no prognostic value of serum albumin was shown. On the other hand, a high WBC count $\left(>8,000 / \mathrm{mm}^{3}\right)$ was a poor prognostic factor in our study. A previous report proposed C-reactive protein (CRP) as a useful prognostic factor of inflammation in EC (21). Similarly to CRP, a high WBC count is considered to reflect systemic inflammation. In our study, patients with a high CRP level tended to have poor survival. However, since CRP was not assessed in approximately one-third of the patients in the pretreatment examination, CRP was excluded from our analysis.

Potential weaknesses of our study are its retrospective nature, the limited sample size, and the lack of histological diagnosis for SCLN metastases. Although further validation of our data is required in a prospective cohort, it is difficult to conduct a randomized controlled trial because of the 
Table II. Univariate and multivariate analyses of overall survival with Cox proportional hazards models.

\begin{tabular}{|c|c|c|c|c|c|c|c|c|c|c|}
\hline \multirow[b]{2}{*}{ Factor } & \multicolumn{3}{|c|}{ Univariate analysis $(n=101)$} & \multicolumn{3}{|c|}{ Multivariate analysis $(n=101)$} & \multicolumn{4}{|c|}{$p$-Value for proportional hazard assumption } \\
\hline & HR & $95 \% \mathrm{CI}$ & $p$-Value & HR & $95 \% \mathrm{CI}$ & $p$-Value & Time & Log time & Rank & $\mathrm{K}-\mathrm{M}$ \\
\hline \multicolumn{11}{|c|}{ Age, years, n (\%) } \\
\hline$<65$ & 1 & & & 1 & & & & & & \\
\hline$\geq 65$ & 1.592 & $0.954-2.655$ & 0.075 & 2.261 & $1.212-4.217$ & 0.010 & 0.532 & 0.406 & 0.368 & 0.361 \\
\hline \multicolumn{11}{|l|}{ PS, n $(\%)$} \\
\hline 0 & 1 & & & 1 & & & & & & \\
\hline $1-2$ & 1.617 & $0.896-2.918$ & 0.110 & 0.755 & $0.396-1.440$ & 0.394 & 0.999 & 0.777 & 0.590 & 0.646 \\
\hline \multicolumn{11}{|l|}{ Location, $\mathrm{n}(\%)$} \\
\hline Ut & 1 & & & 1 & & & & & & \\
\hline $\mathrm{Mt}$ & 0.766 & $0.387-1.515$ & 0.444 & 1.077 & $0.518-2.236$ & 0.843 & 0.852 & 0.791 & 0.807 & 0.793 \\
\hline $\mathrm{Lt}$ & 0.906 & $0.404-2.034$ & 0.811 & 0.971 & $0.397-2.374$ & 0.949 & 0.445 & 0.460 & 0.474 & 0.426 \\
\hline \multicolumn{11}{|l|}{$\mathrm{cT}, \mathrm{n}(\%)$} \\
\hline $\mathrm{T} 1$ & 1 & & & 1 & & & & & & \\
\hline $\mathrm{T} 2$ & 1.706 & $0.329-8.833$ & 0.524 & 0.913 & $0.162-5.134$ & 0.918 & 0.277 & 0.210 & 0.146 & 0.161 \\
\hline $\mathrm{T} 3$ & 4.485 & $1.775-11.333$ & 0.002 & 4.774 & $1.716-13.277$ & 0.003 & 0.083 & 0.110 & 0.117 & 0.102 \\
\hline \multicolumn{11}{|l|}{$\mathrm{cN}, \mathrm{n}(\%)$} \\
\hline No & 1 & & & 1 & & & & & & \\
\hline N1 & 2.934 & $0.898-9.589$ & 0.075 & 1.747 & $0.500-6.103$ & 0.382 & 0.283 & 0.410 & 0.349 & 0.321 \\
\hline $\mathrm{N} 2$ & 2.844 & $0.853-9.483$ & 0.089 & 2.421 & $0.683-8.579$ & 0.171 & 0.445 & 0.566 & 0.488 & 0.469 \\
\hline $\mathrm{N} 3$ & 2.599 & $0.430-15.708$ & 0.298 & 1.844 & $0.227-12.270$ & 0.527 & 0.297 & 0.235 & 0.212 & 0.208 \\
\hline \multicolumn{11}{|l|}{ cIM } \\
\hline Negative & 1 & & & 1 & & & & & & \\
\hline Positive & 0.750 & $0.340-1.653$ & 0.476 & 0.420 & $0.174-1.013$ & 0.053 & 0.537 & 0.552 & 0.886 & 0.836 \\
\hline \multicolumn{11}{|l|}{ WBC } \\
\hline$\leq 8000 / \mathrm{mm}^{3}$ & 1 & & & 1 & & & & & & \\
\hline$>8000 / \mathrm{mm}^{3}$ & 1.752 & $1.033-2.972$ & 0.038 & 2.115 & $1.179-3.794$ & 0.012 & 0.673 & 0.610 & 0.770 & 0.758 \\
\hline \multicolumn{11}{|l|}{ Albumin } \\
\hline$<4.0 \mathrm{~g} / \mathrm{dl}$ & 1 & & & 1 & & & & & & \\
\hline$\geq 4.0 \mathrm{~g} / \mathrm{dl}$ & 0.865 & $0.501-1.494$ & 0.604 & 1.137 & $0.633-2.043$ & 0.667 & 0.173 & 0.164 & 0.064 & 0.058 \\
\hline Overall tests & & & & & & & 0.734 & 0.750 & 0.673 & 0.627 \\
\hline
\end{tabular}

PS: ECOG performance status; Ut: upper thoracic esophagus; Mt: middle thoracic esophagus; Lt: lower thoracic esophagus; cT: clinical tumor depth; WBC: white blood cell counts; HR: hazard ratio; CI: confidence interval; K-M: Kaplan-Meier.

limited number of patients with resectable M1LYM. Moreover, SCLN metastases were determined only by imaging examination. Confirmatory diagnosis of lymph node metastasis should be performed through a histological approach (e.g. fine-needle aspiration). However, the positive predictive value of clinical diagnosis for SCLN metastases was high $(89.3 \%)$ in patients who underwent surgery without preoperative treatment. In addition, clinical staging was determined at a multidisciplinary team conference, and the judgement of clinical SCLN metastases in all groups was made using the same criteria, thus the rate of true SCLN metastases among the three groups can be considered similar.

In our study, almost all cases received neoadjuvant $\mathrm{CF}$ as a preoperative treatment. Although in Western countries, preoperative CRT is a standard treatment for resectable locally advanced EC $(22,23)$, the efficacy of preoperative CRT for resectable M1LYM is still unclear. Further investigation of appropriate preoperative approaches for resectable M1LYM is also warranted.

In conclusion, our study indicates that over $30 \%$ of patients with resectable M1LYM treated with curative intent achieved long-term survival.

\section{Conflicts of Interest}

The Authors have no conflict of interest in regard to this study.

\section{Acknowledgements}

The Authors thank Ms. Emiko Usami for data collection. There was no grant support for this study. 
Table III. Univariate and multivariate analyses of progression-free survival with Cox proportional hazards models.

\begin{tabular}{|c|c|c|c|c|c|c|c|c|c|c|}
\hline \multirow[b]{2}{*}{ Factor } & \multicolumn{3}{|c|}{ Univariate analysis $(\mathrm{n}=101)$} & \multicolumn{3}{|c|}{ Multivariate analysis $(n=101)$} & \multicolumn{4}{|c|}{$p$-Value for the proportional hazard assumption } \\
\hline & HR & $95 \% \mathrm{CI}$ & $p$-Value & HR & $95 \% \mathrm{CI}$ & $p$-Value & Time & Log time & Rank & $\mathrm{K}-\mathrm{M}$ \\
\hline \multicolumn{11}{|c|}{ Age, years, n (\%) } \\
\hline$<65$ & 1 & & & 1 & & & & & & \\
\hline$\geq 65$ & 1.227 & $0.073-1.948$ & 0.385 & 1.397 & $0.815-2.394$ & 0.224 & 0.252 & 0.096 & 0.082 & 0.079 \\
\hline \multicolumn{11}{|l|}{ PS, n (\%) } \\
\hline 0 & 1 & & & 1 & & & & & & \\
\hline $1-2$ & 1.360 & $0.810-2.284$ & 0.245 & 0.773 & $0.431-1.387$ & 0.388 & 0.574 & 0.297 & 0.214 & 0.218 \\
\hline \multicolumn{11}{|c|}{ Location, n (\%) } \\
\hline $\mathrm{Ut}$ & 1 & & & 1 & & & & & & \\
\hline $\mathrm{Mt}$ & 0.825 & $0.444-1.535$ & 0.544 & 0.961 & $0.495-1.865$ & 0.906 & 0.612 & 0.498 & 0.560 & 0.556 \\
\hline $\mathrm{Lt}$ & 1.082 & $0.512-2.283$ & 0.837 & 1.082 & $0.474-2.470$ & 0.851 & 0.483 & 0.576 & 0.755 & 0.736 \\
\hline \multicolumn{11}{|l|}{$\mathrm{cT}, \mathrm{n}(\%)$} \\
\hline $\mathrm{T} 1$ & 1 & & & 1 & & & & & & \\
\hline $\mathrm{T} 2$ & 1.461 & $0.377-5.658$ & 0.583 & 1.133 & $0.279-4.594$ & 0.861 & 0.208 & 0.336 & 0.576 & 0.552 \\
\hline $\mathrm{T} 3$ & 3.634 & $1.651-7.999$ & 0.001 & 3.836 & $1.565-9.403$ & 0.003 & 0.046 & 0.027 & 0.056 & 0.051 \\
\hline \multicolumn{11}{|l|}{$\mathrm{cN}, \mathrm{n}(\%)$} \\
\hline No & 1 & & & 1 & & & & & & \\
\hline $\mathrm{N} 1$ & 2.088 & $0.823-5.301$ & 0.121 & 1.576 & $0.571-4.348$ & 0.380 & 0.919 & 0.616 & 0.568 & 0.585 \\
\hline $\mathrm{N} 2$ & 1.489 & $0.571-3.886$ & 0.416 & 1.233 & $0.445-3.418$ & 0.687 & 0.903 & 0.778 & 0.794 & 0.798 \\
\hline N3 & 2.728 & $0.725-10.268$ & 0.138 & 2.224 & $0.531-9.313$ & 0.274 & 0.771 & 0.698 & 0.552 & 0.549 \\
\hline \multicolumn{11}{|l|}{ cIM, n (\%) } \\
\hline Negative & 1 & & & 1 & & & & & & \\
\hline Positive & 0.953 & $0.488-1.858$ & 0.887 & 0.634 & $0.299-1.343$ & 0.234 & 0.665 & 0.878 & 0.957 & 0.978 \\
\hline \multicolumn{11}{|l|}{ WBC, n (\%) } \\
\hline$\leq 8000 \mathrm{~mm}^{3}$ & 1 & & & 1 & & & & & & \\
\hline$>8000 \mathrm{~mm}^{3}$ & 1.497 & $0.908-2.469$ & 0.114 & 1.659 & $0.958-2.871$ & 0.071 & 0.820 & 0.483 & 0.391 & 0.405 \\
\hline \multicolumn{11}{|c|}{ Albumin, n (\%) } \\
\hline$<4.0 \mathrm{~g} / \mathrm{dl}$ & 1 & & & 1 & & & & & & \\
\hline$\geq 4.0 \mathrm{~g} / \mathrm{dl}$ & 1.098 & $0.661-1.823$ & 0.719 & 1.434 & $0.822-2.503$ & 0.204 & 0.304 & 0.336 & 0.502 & 0.479 \\
\hline Overall tests & & & & & & & 0.811 & 0.460 & 0.450 & 0.445 \\
\hline
\end{tabular}

PS: ECOG performance status; Ut: upper thoracic esophagus; Mt: middle thoracic esophagus; Lt: lower thoracic esophagus; cT: clinical tumor depth; WBC: white blood cell counts; HR: hazard ratio; CI: confidence interval; K-M: Kaplan-Meier.

Table IV. Comparison of survival data in this study with those in historical cohorts.

\begin{tabular}{|c|c|c|c|c|}
\hline Study (Ref) & $\begin{array}{c}\text { Clinical } \\
\mathrm{CR}\end{array}$ & $\begin{array}{l}\text { Median PFS } \\
\text { (months) }\end{array}$ & $\begin{array}{c}\text { MST } \\
\text { (months) }\end{array}$ & OS \\
\hline CF-RT for Stage II/III (JCOG9906) (17) & $62.2 \%$ & 12 & 29 & $37 \%$ (5-year) \\
\hline CRT for resectable M1LYM & $52.6 \%$ & 8.5 & 22 & $20.5 \%$ (5-year \\
\hline Neo-CF + surgery for stage II/III (JCOG9907) (18) & - & 36 & Not reached & $60.1 \%$ (5-year) \\
\hline Surgery with perioperative treatment for resectable M1LYM & - & 9.1 & 27.5 & $43 \%$ (5-year) \\
\hline Standard CF-RT for locally advanced unresectable disease (JCOG0303) (19) & Not assessed & Not given & 13.1 & $\begin{array}{l}55.9 \% \text { (1-year } \\
25.9 \% \text { (3-year }\end{array}$ \\
\hline CF for metastatic disease (JCOG9407) (20) & $2.8 \%$ & Not given & 6.7 & $27.8 \%$ (1-year \\
\hline
\end{tabular}

CR: Complete remission; PFS: progression-free survival; MST: median survival time; OS: overall survival; CF: cisplatin +5 -fluorouracil; RT: radiotherapy; CRT: chemoradiotherapy; M1LYM: thoracic esophageal cancer with supraclavicular lymph node metastases. 


\section{References}

1 Kuwano H, Nishimura Y, Oyama T, Kato H, Kitagawa Y, Kusano M, Shimada H, Takiuchi H, Toh Y, Doki Y, Naomoto Y, Matsubara H, Miyazaki T, Muto $M$ and Yanagisawa A: Guidelines for diagnosis and treatment of carcinoma of the esophagus; April 2012 edited by the Japan esophageal society. Esophagus 12: 1-30, 2015.

2 Talsma K, van Hagen P, Grotenhuis BA, Steyerverg EW, Tilanus HW, van Lanschot JJ and Wijnhoven BP: Comparison of the 6th and 7th editions of the UICC-AJCC TNM classification for esophageal cancer. Ann Surg Oncol 19: 2142-2148, 2012.

3 Sobin LH GM and Wittekind $\mathrm{CH}$ : TNM Classification of Malignant Tumours. Seventh Edition. United Kingdom, WileyBlackwell, 2009.

4 NCCN Clinical Practice Guidelines in Oncology Esophageal and Esophagogastric Junction Cancers Version 2 (2015). Available from: http://www.nccn.org/professionals/physician_gls/pdf/ esophageal.pdf

5 Tachimori Y, Ozawa S, Numasaki H, Matsubara H, Shinoda M, Toh Y and Udagawa H: Supraclavicular node metastasis from thoracic esophageal carcinoma: A surgical series from a Japanese multi-institutional nationwide registry of esophageal cancer. J Thoracic Cardiovasc Surg 148: 1224-1229, 2014.

6 Udagawa H, Ueno M, Shinohara H, Haruta S, Kaida S, Nakagawa $\mathrm{M}$ and Tsurumaru $\mathrm{M}$ : The importance of grouping of lymph node station and rationale of three-field lymphadenectomy for thoracic esophageal cancer. J Surg Oncol 106: 742-747, 2012.

7 Japan Esophageal Society: Japanese Classification of Esophageal Cancer, Tenth Edition: Part I. Esophagus 6: 1-25, 2009.

8 Grambsch PM and Therneau TM: Proportional hazards tests and diagnostics based on weighted residuals. Biometrika 81: 515526, 1994.

9 Isono K, Sato H and Nakayama K: Result of a nationwide study on the three-field lymph node dissection of esophageal cancer. Oncology 48: 411-429, 1991.

10 Akiyama H, Tsurumaru M and Udagawa $\mathrm{H}$ : Radical lymph node dissection for cancer of the thoracic esophagus. Ann Surg 220: 364-373, 1994.

11 Tachimori Y, Kato $\mathrm{H}$ and Watanabe H: Surgery for thoracic esophageal carcinoma with clinically positive cervical nodes. J Thorac Cardiovasc Surg 116: 954-959, 1998.

12. Raoul JL, Le Prise E, Meunier B, Julienne V, Etienne PL, Gosselin $\mathrm{M}$ and Launois B: Combined radiothemotherapy for postoperative recurrence of oesophageal cancer. Gut 37: 174-176, 1995.

13 Shioyama Y, Nakamura K, Ohga S, Nomoto S, Sasaki T, Yamaguchi T, Toba T, Yoshitake T, Terashima H and Honda H: Radiation therapy for recurrent esophageal cancer after surgery: clinical results and prognostic factors. Jpn J Clin Oncol 37: 918923, 2007.

14 Kato K, Muro K, Minashi K, Ohtsu A, Ishikura S, Boku N, Takiuchi H, Komatsu Y, Miyata Y and Fukuda H: Phase II study of chemoradiotherapy with 5-fluorouracil and cisplatin for stage II-III esophageal squamous cell carcinoma: JCOG trial (JCOG 9906). Int J Radiation Oncology Biol Phys 81: 684-690, 2011.

15 Ando N, Kato H, Igaki H, Shinoda M, Ozawa S, Shimizu H, Nakamura T, Yabusaki H, Aoyama N, Kurita A, Ikeda K, Kanda $\mathrm{T}$, Tsujinaka T, Nakamura $\mathrm{K}$ and Fukuda $\mathrm{H}$ : A randomized trial comparing postoperative adjuvant chemotherapy with cisplatin and 5-fluorouracil versus preoperative chemotherapy for localized advanced squamous cell carcinoma of the thoracic esophagus (JCOG9907). Ann Surg Oncol 19: 68-74, 2012.

16 Shinoda M, Ando N, Kato K, Ishikura S, Kato H, Tsubosa Y, Minashi K, Okabe H, Kimura Y, Kawano T, Kosugi S, Toh Y, Nakamura $\mathrm{K}$ and Fukuda H: Randomized study of low-dose versus standard-dose chemoradiotherapy for unresectable esophageal squamous cell carcinoma (JCOG0303). Cancer Sci 106: 407-412, 2015.

17 Hayashi K, Ando N, Watanabe H, Ide H, Nagai K, Aoyama N, Takiyama $\mathrm{W}$, Ishida $\mathrm{K}$, Isono $\mathrm{K}$, Makuuchi $\mathrm{H}$, Imamura $\mathrm{M}$, Shinoda M, Ikeuchi S, Kabuto T, Yamana H and Fukuda H: Phase II evaluation of protracted infusion of cisplatin and 5fluorouracil in advanced squamous cell carcinoma of the esophagus: a Japanese Esophageal Oncology Group (JEOG) trial (JCOG9407). Jpn J Clin Oncol 31: 419-423, 2001.

18 Zhang SS, Yang H, Luo KJ, Huang QY, Chen JY, Yang F, Cai XL, Xie X, Liu QW, Bella AE, Hu RG, Wen J, Hu Y and Fu JH: The impact of body mass index on complication and survival in resected oesophageal cancer: a clinical based cohort and metaanalysis. Br J Cancer 109: 2894-2903, 2013.

19 Zhu Z, Chen H, Yu W, Fu X, Xiang J, Li H, Zhang Y, Sun M, Wei Q, Zhao W and Zhao K: Number of negative lymph nodes is associated with survival in thoracic esophageal squamous cell carcinoma patients undergoing three-field lymphadenectomy. Ann Surg Oncol 21: 2857-2863, 2014.

20 Yokota T, Ando N, Igaki H, Shinoda M, Kato K, Mizusawa J, Katayama H, Nakamura K, Fukuda $\mathrm{H}$ and Kitagawa $\mathrm{Y}$ : Prognostic factors in patients receiving neoadjuvant 5fluorouracil plus cisplatin for advanced esophageal cancer (JCOG9907). Oncology 89: 143-151, 2015.

21 Huang Y, Feng JF, Liu JS and Chen QX: Prognostic role of serum C-reactive protein in esophageal cancer: a systematic review and meta-analysis. Ther Clin Risk Manag 11: 89-94, 2015.

22 Sjoquist KM, Burmeister BH, Smithers BM, Zalcberg JR, Simes RJ, Barbour A and Gebski V: Survival after neoadjuvant chemotherapy or chemoradiotherapy for resectable oesophageal carcinoma: an updated meta-analysis. Lancet Oncol 12: 681-92, 2011.

23 van Hagen P, Hulshof MC, van Lanschot JJ, Steyerberg EW, van Berge Henegouwen MI, Wijnhoven BP, Richel DJ, Nieuwenhuijzen GA, Hospers GA, Bonenkamp JJ, Cuesta MA, Blaisse RJ, Busch OR, ten Kate FJ, Creemers GJ, Punt CJ, Plukker JT, Verheul HM, Spillenaar Bilgen EJ, van Dekken H, van der Sangen MJ, Rozema T, Biermann K, Beukema JC, Piet AH, van Rij CM, Reinders JG, Tilanus HW and van der Gaast A: Preoperative chemoradiotherapy for esophageal or junctional cancer. N Engl J Med 366: 2074-2084, 2012.

24 Oken MM, Creech RH, Tormey DC, Horton J, Davis TE, McFadden ET and Carbone PP: Toxicity and response criteria of the Eastern Cooperative Oncology Group. Am J Clin Oncol 5: 649-655, 1982.

25 Eisenhauer EA, Therasse P, Bogaerts J, Schwartz LH, Sargent D, Ford R, Dancey J, Arbuck S, Gwyther S, Mooney M, Rubinstein L, Shankar L, Dodd L, Kaplan R, Lacombe D and Verweij J: New response evaluation criteria in solid tumours: Revised RECIST guideline (version 1.1). Eur J Cancer 45: 228-247, 2009.

Received March 13, 2017 Revised April 5, 2017 Accepted May 5, 2017 